\title{
Die Corporate Governance im neuen japanischen Gesellschaftsrecht
}

Unter besonderer Berücksichtigung der Aufgaben von Verwaltungs- und Prüferrat

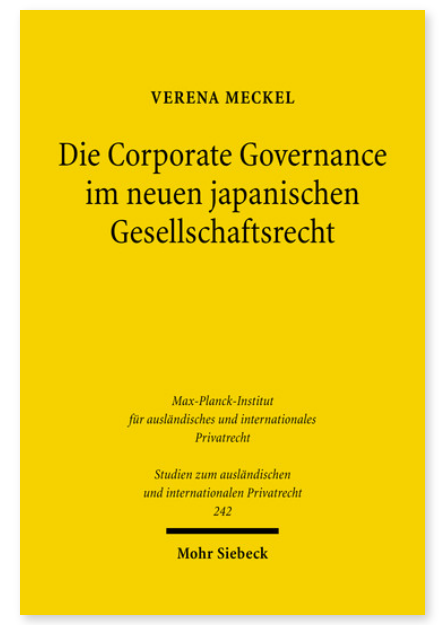

2010. XXII, 222 Seiten. StudIPR 242

ISBN 978-3-16-151427-2

DOI 10.1628/978-3-16-151427-2

eBook PDF $69,00 €$

ISBN 978-3-16-150380-1

fadengeheftete Broschur $69,00 €$
Unter dem Begriff Corporate Governance ist gute und verantwortungsvolle Unternehmensführung und -überwachung zu verstehen. Nachdem Japan nahezu 100 Jahre im Wesentlichen dem Vorbild der deutschen und damit dualistischen Unternehmensverfassung gefolgt ist, wird mit der Gesellschaftsrechtsreform 2005/2006 die bereits nach 1945 eingeleitete Trendwende hin zum amerikanischen Recht verfestigt. Neben einer umfassenden Darstellung der Corporate GovernanceStrukturen des neuen Gesellschaftsgesetzes hat Verena Meckel vor Ort auch die Auswirkungen der Gesetzesänderung in der Praxis untersucht. Dabei fand sie heraus, dass die gesetzliche Betonung externer Direktoren und Prüfer - ein Kernpunkt der Reform - im Widerspruch zur Konsensmentalität japanischer Unternehmen steht, die nach wie vor auf sehr engen Beziehungen zu und unter ihren Mitarbeitern basieren, auch wenn sich diese Verbindungen ganz allmählich zu lockern scheinen.

Verena Meckel Geboren 1982; 2002-07 Studium der Rechtswissenschaft in Bonn, 2007 wissenschaftliche Mitarbeit am Zentrum für Europäisches Wirtschaftsrecht der Universität Bonn; 2008 Forschungsaufenthalt an der Waseda Universität in Tokyo (Japan); 2009 Promotion, derzeit Referendariat beim LG Bonn (OLG-Bezirk Köln).

Jetzt bestellen:

https://mohrsiebeck.com/buch/die-corporate-governance-im-neuen-japanischen-gesellschaftsrecht-9783161514272? no_cache=1

order@mohrsiebeck.com

Telefon: +49 (0)7071-923-17

Telefax: $+49(0) 7071-51104$ 